\title{
A EDUCAÇÃO AMBIENTAL NA CONCEPÇÃO DOS DOCENTES DO CURSO DE GRADUAÇÃO EM ENGENHARIA MECÂNICA
}

\author{
Fabiana Aparecida Vilaça ${ }^{1}$ \\ Ana Claudia Siqueira ${ }^{2}$ \\ Rita de Cássia Frenedozo 3
}

Resumo: A Educação Ambiental, quando aplicada em sala de aula, é um caminho para mudar atitudes, estimulando a consciência ambiental, a sustentabilidade e a cidadania. Porém, nem sempre os docentes estão preparados para discutir a temática socioambiental. Assim, a necessidade de saber a concepção dos professores do curso de graduação em Engenharia Mecânica sobre Educação Ambiental constitui-se no objetivo desta pesquisa que foi realizada em uma Universidade particular da cidade de São Paulo. Os dados obtidos demonstraram uma atitude tendendo a "ingenuidade" dos docentes para as questões socioambientais, o que pode ser explicado pelo desenvolvimento histórico da Engenharia e pela formação profissional destes.

Palavras-chave: Educação Ambiental; Práticas Docentes; Engenharia Mecânica.

\footnotetext{
${ }^{1}$ Universidade Cruzeiro do Sul. E-mail: fabiana_bio@hotmail.com

2 Universidade Cruzeiro do Sul. E-mail: anaclaudia170572@gmail.com

3 Universidade Cruzeiro do Sul. E-mail: ritafrenedozo@yahho.com.br
} 


\section{Introdução}

A sociedade atual vive em um sistema que está esgotando os recursos naturais em troca do desenvolvimento econômico e tecnológico. Vivemos em um mundo consumista, onde os produtos possuem tempo de vida útil muito curto e a mídia faz pressão para que os indivíduos tenham sempre o celular mais moderno, o sapato da moda, o carro do ano. É necessário revermos nosso conceito de desenvolvimento a qualquer custo, pois o planeta já está demonstrando sinais de que não suporta mais tanta exploração e desequilíbrio.

Segundo Seiffert (2011), essa necessidade de reestruturação da produção fez surgir o conceito de desenvolvimento sustentável, que, por sua vez, ainda está em construção, pois trata-se de um assunto muito amplo que vai além da questão do lixo e preservação da biodiversidade.

Acselrad (2001) denomina de matrizes discursivas as diferentes interpretações conferidas ao conceito de desenvolvimento sustentável, podendo ainda existir a matriz da autossuficiência (desvinculação dos fluxos de mercado mundial); a matriz da eficiência (combate ao desperdício) e a matriz da equidade (articulação entre justiça social e preservação ambiental). Tais matrizes podem ser um exemplo da maneira como o desenvolvimento sustentável deve ser tratado nas instituições de ensino superior, inclusive nos cursos de Engenharia Mecânica, alvo dessa pesquisa, pois, segundo Sauvé (1997) todo processo educativo deveria ser reformulado para o desenvolvimento sustentável.

A Educação Ambiental nas universidades, entretanto, não deve ter princípios conservacionista cujos ensinamentos conduzem ao uso racional dos recursos ambientais e à manutenção de um nível ótimo de produtividade dos ecossistemas naturais ou gerenciados pelo homem, mas sim, ser uma educação voltada para o meio ambiente com mudança de valores e atitudes, em uma nova visão de mundo, que, segundo Sauvé (2005), deve tratar da nossa relação com o planeta em que vivemos e com as pessoas que, conosco, neste planeta vivem.

Assim, os docentes devem saber transmitir aos seus alunos que o impacto do homem sobre a natureza é inevitável, porém, nem sempre este impacto é, ou precisa ser, negativo. Para intervir de modo apropriado, o educador deve levar em conta as múltiplas facetas dessa relação com a natureza, que correspondem a modos diversos e complementares de apreender o meio ambiente (SAUVÉ, 2005).

O curso de graduação em Engenharia Mecânica está relacionado diretamente com o desenvolvimento tecnológico e infraestrutura de um país. Portanto, precisamos de engenheiros mecânicos que saibam implementar seus conhecimentos técnicos adquiridos na universidade levando em conta as características sociais e ambientais da realidade onde estão inseridos. O ensino superior deve contribuir para a formação cidadã dos engenheiros para 
que estes sejam capazes de sanar os problemas socioambientais mais emergentes.

Diante disso, a preocupação com a formação dos futuros engenheiros mecânicos nos leva a pensar também na formação dos docentes que atuam nos cursos de graduação em Engenharia Mecânica, principalmente no que diz respeito a concepção dos mesmos sobre Educação Ambiental. Será que os professores universitários estão contribuindo para formação de engenheiros mecânicos conscientes e voltados para o bem-estar social? Ou, os docentes preocupam-se apenas em formar profissionais que buscam o desenvolvimento econômico e tecnológico a qualquer custo?

Assim, torna-se urgente a necessidade de se refletir sobre o ensino de Engenharia, para que os futuros engenheiros possam ser atuantes em questões como desenvolvimento sustentável e Educação Ambiental e não somente reproduzirem modelos sociais, verdades inquestionáveis e buscarem o desenvolvimento econômico a qualquer preço.

Julgamos ser essencial que um professor do curso de graduação em Engenharia Mecânica conheça a dinâmica e os processos vitais da natureza e tenha uma formação epistemológica e sociocrítica para levar seus discentes a interpretarem a realidade em que vivem e construírem conhecimento e consciência frente aos problemas ambientais enfrentados em seu dia-a-dia, no bairro onde moram, no país onde vivem, no planeta em que habitam.

Logo, a concepção desses professores sobre Educação Ambiental está relacionada à sua formação profissional e aos seus saberes docentes, que devem ser compreendidos numa relação direta com as condições que estruturam seu trabalho (TARDIF, 2002). Para terem consciência da necessidade da aplicação da Educação Ambiental em suas disciplinas, os docentes do curso de graduação em Engenharia Mecânica devem apostar no desenvolvimento de seus saberes experienciais, segundo Tardif (2002), aqueles que resultam da vivência de situações específicas, tais como observar os prejuízos que a devastação de um ecossistema leva para a sociedade que antes habitava e dependia dele. Ou ainda, vivenciar o drama social das vítimas decorrentes de acidentes com material radioativo.

Assim, tendo em vista que as práticas pedagógicas e a concepção sobre Educação Ambiental dos professores universitários contribuem para a formação dos discentes, o objetivo dessa dissertação de mestrado é analisar a concepção dos docentes do curso de Engenharia Mecânica de uma universidade particular da cidade de São Paulo sobre Educação Ambiental.

\section{Metodologia}

A presente pesquisa é de natureza quali-quantitativa, onde foram observados aspectos referentes à concepção dos docentes do curso de Engenharia Mecânica sobre Educação Ambiental. A conjugação da pesquisa qualitativa com a quantitativa, segundo Goldenberg (1999), demonstra que não 
há uma única técnica, um único meio válido de coletar os dados em todas as pesquisas, pois o método utilizado vai depender das questões levantadas no início da pesquisa e quais os problemas que se quer responder, levando-se a acreditar que há uma interdependência entre os diversos métodos de pesquisa existentes.

Este estudo foi realizado em uma Universidade Particular, situada na zona leste da cidade de São Paulo e os sujeitos dessa pesquisa foram os docentes do curso de graduação em Engenharia Mecânica, que foram selecionados aleatoriamente, de acordo com a disponibilidade e interesse em participar da pesquisa. Foi enviado, via e-mail, um termo de consentimento e livre esclarecimento a 10 docentes, juntamente com um questionário contendo 4 questões de múltipla escolha e informações e orientações breves sobre o seu preenchimento.

As fontes de coleta de dados foi a aplicação do questionário COCTS (Cuestionario de Opiniones sobre la Ciencia, la Tecnologia y la Sociedade), segundo Bispo-Filho (2012), uma ferramenta muito valiosa por sua amplitude e flexibilidade de uso.

O questionário COCTS tem como objetivo buscar as concepções existentes no público em geral sobre determinado assunto relacionado a ciência e tecnologia e suas relações com a sociedade (VÁZQUEZ - ALONSO et al., 2006). Este instrumento está baseado no uso de um conjunto de questões de opção de múltipla escolha, considerado como um dos melhores instrumentos já elaborados com emprego de papel e lápis para avaliar as atitudes sobre temas e questões relacionadas a natureza da ciência (BISPOFILHO; SEPINI; MACIEL, 2011).

O COCTS, originalmente, possui mais de 100 questões de múltipla escolha, porém, para adequar e adaptar o referido questionário ao objetivo dessa pesquisa, o mesmo foi aplicado com cortes, priorizando-se questões que evidenciam conceitos ambientais, a fim de facilitar e delimitar sua ação.

A estrutura do questionário oferece, entre as questões, diferentes alternativas relativas à Natureza da Ciência, organizadas em temas e subtemas, tais como: Ciência e Tecnologia, Influência da Sociedade sobre a Ciência, Tecnologia e Meio Ambiente, Influência da Ciência Escolar sobre a Sociedade e Natureza do Conhecimento Científico.

Por sua estrutura, o COCTS possibilita desenvolver não só análises quantitativas, mas também qualitativas sobre a temática proposta por cada questão, através das frases que compõem cada item e as temáticas mais amplas que abrangem o conjunto de questões. (MANASSERO; VÁZQUEZ; ACEVEDO, 2003)

As questões do COCTS utilizadas para esta pesquisa foram aquelas relacionadas a influência da ciência e tecnologia sobre a sociedade e meio ambiente, designadas pelos seguintes números 40161, 40211, 40321 e 40411. 


\section{Resultados e Discussões}

Dos 10 questionários enviados por email aos docentes do curso de Graduação em Engenharia Mecânica da Universidade onde foi realizada a pesquisa, apenas 7 foram respondidos. Assim, trabalhamos com uma amostra de 7 professores, que foram designados respondentes "1", "2", "3", “4", "5", "6" e "7", com o intuito e manter o sigilo e impessoalidade aos participantes da pesquisa.

Para a questão "40161": "A industrialização pesada está contaminando enormemente os países desenvolvidos. Portanto, é uma decisão responsável transferir essas indústrias para os países subdesenvolvidos, onde a contaminação ambiental ainda não é tão grande", para a alternativa A: "A industrialização pesada deveria ser transferida para os países subdesenvolvidos para salvar os países desenvolvidos e suas futuras gerações da poluição", considerada como "Ingênua", pelo consenso dos juízes do COCTS, o professor "3" considerou a mesma adequada (7), gerando o índice atitudinal "-0,5", que, conforme Bispo-Filho (2012), por ser negativo, corresponde a uma atitude "ingênua" do respondente.

$\mathrm{Na}$ alternativa $\mathrm{B}$, da mesma questão: "É difícil de decidir. Transferir as indústrias ajudaria os países pobres a prosperar e também reduziria a poluição nos países desenvolvidos. Porém, não é certo contaminar o meio ambiente de outros lugares", considerada como "Plausível" pela maioria dos juízes do COCTS, os professores "2" e "3", com suas respostas, geraram um índice atitudinal "-1", indicando uma visão totalmente ingênua sobre a questão abordada.

Já na alternativa C da questão 40161: "Não é questão de onde está localizada a industrialização pesada. Os efeitos da poluição são globais sobre a Terra", considerada "Adequada" pelo consenso dos juízes do COCTS, todos os professores optaram pelo item 9, concordando totalmente com o consenso dos juízes, gerando um índice atitudinal "1", demonstrando uma visão adequada diante do problema em questão.

A alternativa D: "A industrialização pesada não deveria ser transferida para os países subdesenvolvidos porque transferir as indústrias não é uma forma responsável de resolver o problema da poluição. O certo seria reduzir ou eliminar a poluição nos países desenvolvidos ao invés de criar problemas em outro lugar", também considerada como "Adequada" pelo consenso dos juízes do COCTS, obteve a geração de dois índices atitudinais "- 0,75 ", dos professores "6" e "7", que optaram pelo item 2 como resposta, discordando altamente do consenso dos juízes. Ou seja, esses dois docentes, de acordo com Bispo- Filho (2012), possuem uma visão bastante ingênua sobre o problema abordado.

A Alternativa E da questão 40161: "A industrialização pesada não deveria ser transferida para os países subdesenvolvidos porque esses países já possuem problemas suficientes e a poluição seria mais um", considerada "Plausível" pela maioria dos juízes do COCTS foi aquela que mais gerou 
índices atitudinais negativos ou iguais a zero ou seja, "ingênuos", sendo que três professores concordaram totalmente com a alternativa, dois discordaram altamente, um teve uma concordância mediana e outro uma discordância mediana.

Para a alternativa $\mathrm{F}$ da questão 40161: "A industrialização pesada não deveria ser transferida para os países subdesenvolvidos porque a poluição deve ser limitada tanto o quanto for possível. Externá-las criaria mais danos", considerada como "Adequada" pelo consenso dos juízes do COCTS, os professores "6" e "7" assinalaram o item 2, discordando altamente do consenso dos juízes, gerando um índice atitudinal de "- 0,75 ", que, segundo Bispo- Filho (2012), demonstra uma visão ingênua sobre o assunto abordado.

O índice atitudinal global para cada uma das respostas da questão "40161" do COCTS foi realizado através da média dos índices de cada uma das respostas atribuídas a referente questão, conforme preconizou Bispo-Filho (2012), gerando o Gráfico 1.

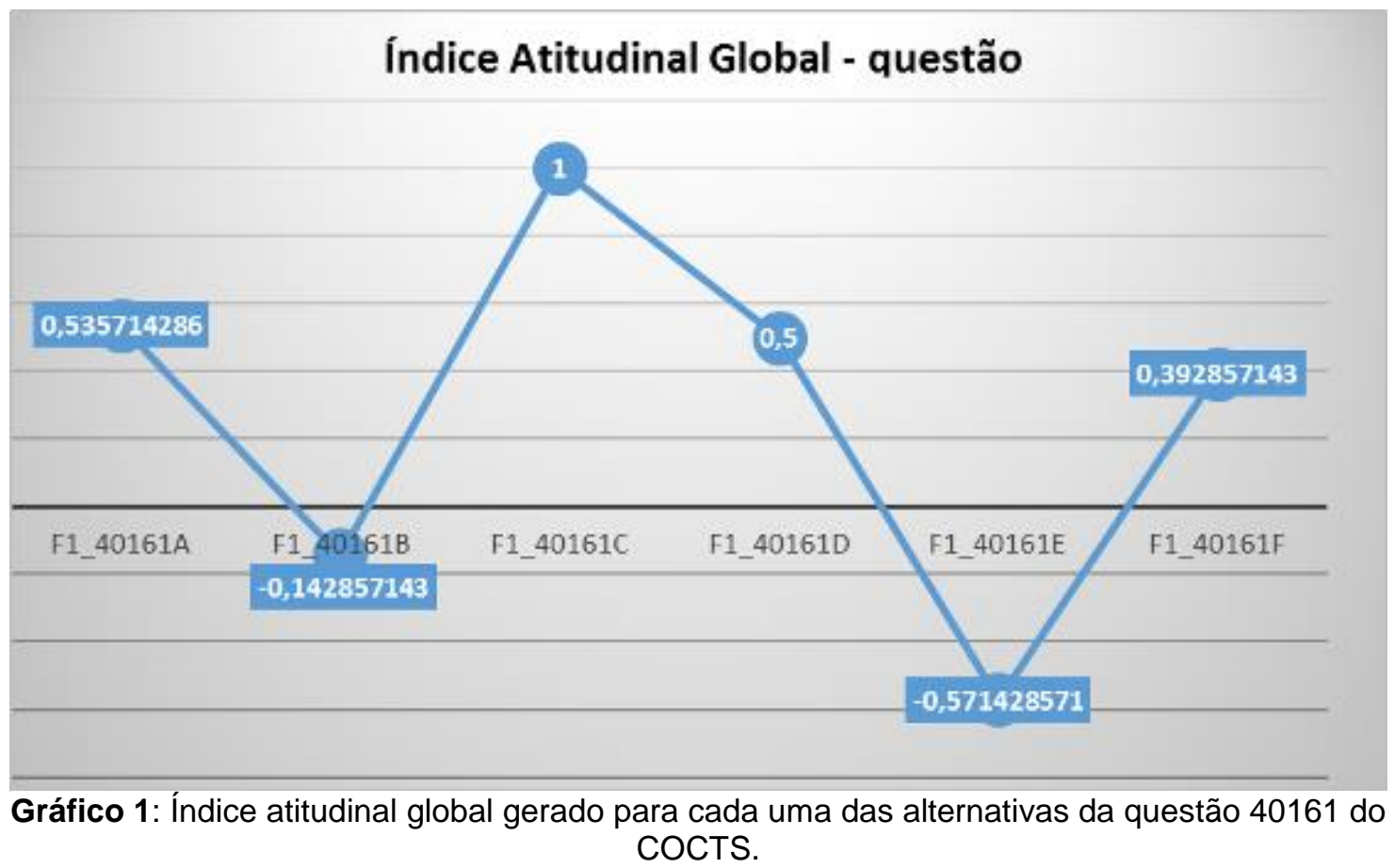

Pelo índice global, observamos que, para a questão 40161: "A industrialização pesada está contaminando enormemente os países desenvolvidos. Portanto, é uma decisão responsável transferir essas indústrias para os países subdesenvolvidos, onde a contaminação ambiental ainda não é tão grande". As alternativas B: "É difícil de decidir. Transferir as indústrias ajudaria os países pobres a prosperar e também reduziria a poluição nos países desenvolvidos. Porém, não é certo contaminar o meio ambiente de outros lugares" e E: "A industrialização pesada não deveria ser transferida para

Revbea, São Paulo, V. 13, № 2: 137-152, 2018. 
os países subdesenvolvidos porque esses países já possuem problemas suficientes e a poluição seria mais um", foram aquelas que apresentaram índice global negativo, demonstrando uma visão ingênua dos respondentes sobre o assunto.

Para a questão "40211" do COCTS: Os cientistas e engenheiros devem ser os únicos profissionais a decidir sobre assuntos científicos do nosso país porque são as pessoas que melhor entendem sobre os tipos de energia para o futuro (nuclear, hidráulica, queima de petróleo), índices permitidos de contaminação do ar em nosso país (emissões industriais de enxofre, emissões de gases dos escapamentos de carros e caminhões, emissões de gases ácidos em poços de petróleo), futuro da biotecnologia (DNA recombinante, engenharia genética), técnicas de reprodução assistida e manipulação genética e desarmamento nuclear", para a alternativa A: "Os cientistas e engenheiros são os únicos profissionais que devem decidir sobre assuntos científicos porque possuem formação e conhecimentos que lhes conferem uma melhor compreensão sobre temas de ciência e tecnologia", considerada como "Ingênua", pelo consenso dos juízes do COCTS, os professores "1", "3" e "7" concordaram medianamente com a mesma (pontuação 7), gerando o índice atitudinal " $-0,5$ " e o professor " 6 " concordou parcialmente, gerando o índice atitudinal "-0,25", o que conforme Bispo-Filho (2012), por ser negativo, corresponde a uma atitude "ingênua" dos respondentes.

$\mathrm{Na}$ alternativa $\mathrm{B}$, da mesma questão: "Os cientistas e engenheiros são os únicos profissionais que devem decidir sobre assuntos científicos porque possuem conhecimentos e podem tomar decisões melhores do que aquelas tomadas pelo governo, que são burocráticas ou melhores do que aquelas tomadas pelas empresas privadas, que possuem interesses particulares", considerada, novamente, como "Ingênua" pelo consenso dos juízes do COCTS, os professores "1", "3" com suas respostas, geraram um índice atitudinal "-1", indicando uma atitude totalmente ingênua sobre a questão abordada. Já os professores "6" e "7" atribuíram a pontuação 8 em suas respostas (concordam altamente), gerando o índice atitudinal "- 0,75 ", que indica, por parte dos mesmos, uma atitude altamente ingênua frente à questão abordada.

Já na alternativa C da questão "40211': "Os cientistas e engenheiros são os únicos profissionais que devem decidir sobre assuntos científicos porque possuem formação e dados que lhes conferem melhor compreensão, porém os cidadãos envolvidos com essas decisões deveriam ser informados e consultados", classificada como "Plausível" pela maioria dos juízes do COCTS, dois dos professores (" 1 " e " 5 ") responderam 9, concordando totalmente com a alternativa "C", gerando um índice atitudinal "-1", demonstrando uma atitude totalmente ingênua sobre a questão. Outros cinco professores ("2", "3", "6" e "7"), atribuíram o valor 8 em suas respostas, concordando altamente com a questão, gerando então um índice atitudinal "-0,5" e demonstrando um atitude altamente ingênua sobre o problema. Um professor ("4"), atribuiu a nota 7 à alternativa $\mathrm{C}$, concordando medianamente com a mesma, o que gerou um índice atitudinal "0", ou seja, parcialidade sobre a problemática discutida.

Revbea, São Paulo, V. 13, № 2: 137-152, 2018.

revista brasileira educação ambiental 
A alternativa D: "As decisões devem ser tomadas de maneira compartilhada. As opiniões de cientistas, engenheiros, outros especialistas e cidadãos envolvidos devem ser levadas em conta nas decisões que afetam a nossa sociedade", considerada como "Adequada" pelo consenso dos juízes do COCTS não gerou índices atitudinais individuais negativos, demonstrando uma atitude adequada dos mesmos para a questão abordada. Quatro professores ("1", "2", "4" e '5"), atribuíram o valor 9 em suas respostas, concordando totalmente com a alternativa D, gerando o índice atitudinal "1". Outros dois respondentes ("6" e "7"), optaram pelo valor 8 em suas respostas, concordando altamente com o consenso dos juízes, gerando o índice atitudinal " 0,75 " e apenas um docente ("3"), atribuiu o valor 7 em sua resposta, gerando o índice atitudinal " 0,5 ".

A Alternativa E da questão "40211": "O governo deve decidir pois é um tema basicamente político, porém, cientistas e engenheiros devem aconselhar", considerada "Plausível" pelo consenso dos juízes do COCTS gerou quatro índices atitudinais individuais "-1", devido aos professores respondentes "1", "3", "4" e " 5 " terem atribuído o valor 1 em suas respostas, discordaram totalmente com o consenso dos juízes, o que, segundo Bispo - Filho (2012), leva-nos a acreditar em uma atitude ingênua destes professores diante da questão abordada. O respondente "2", atribuiu em sua resposta o valor "3", gerando o índice atitudinal " 0 ", o que indica parcialidade frente ao problema. Os professores " 6 ' e " 7 ", através de suas respostas, também geraram um índice atitudinal "0", porém, por terem atribuído o valor "7" em suas respostas, ou seja, concordando medianamente com o consenso dos juízes do COCTS.

Para a alternativa F da questão "40211": "Os cidadãos devem decidir, pois tais decisões afetam a todos, porém, cientistas e engenheiros devem aconselhar", considerada como "Adequada" pela maioria dos juízes do COCTS, o professor " 5 " atribuiu o valor "9" em sua resposta (concordo totalmente), gerando o índice atitudinal "1", o que significa dizer que o mesmo pois uma atitude adequada frente ao problema discutido na questão. Já os professores respondentes "2" e " 4 ", atribuíram o valor " 1 " em duas respostas, discordando totalmente dos juízes do COCTS, gerando o índice atitudinal "-1", o que levanos a acreditar que ambos possuam uma atitude ingênua diante da questão. Os professores "1" e " 3 " atribuíram o valor "6" em suas respostas, gerando o índice atitudinal "0,25" (atitude parcialmente adequada). O respondente "4" atribuiu o valor "4" em sua resposta, gerando o índice atitudinal "- 0,25 ", o que indica uma atitude parcialmente ingênua para a questão e, por fim, o professor "7", atribuiu o valor " 5 " para a alternativa $F$, gerando o índice atitudinal "0", ou seja, uma atitude de parcialidade diante do problema proposto.

A alternativa G da questão "40211": "Os cidadãos devem decidir, porque servem como controle para os cientistas e engenheiros. Estes possuem opiniões idealistas e estreitas sobre o tema e, portanto, prestam pouca atenção nas consequências", considerada como "Plausível" pela maioria dos juízes do COCTS, gerou cinco índices atitudinais negativos, sendo dois "- 1 " e três "-0,5", indicando uma atitude ingênua da maioria dos professores respondentes diante 
da questão abordada. Apenas dois professores ("1" e " 5 "), através de suas respostas, obtiveram o índice atitudinal " 0,5 ", indicando parcialidade diante do problema proposto.

A Alternativa H da questão "40211": "Depende do tipo de decisão a tomar; não é a mesma coisa decidir sobre o desarmamento nuclear e um bebê. No primeiro caso, somente os cientistas devem decidir, no segundo caso, apenas os cidadãos interessados devem decidir", também considerada "Plausível" pela maioria dos juízes dos COCTS, gerou seis índices atitudinais negativos, sendo três "-1" e três "- 0,5 ", indicando, mais uma vez, uma atitude ingênua dos participantes da pesquisa para a questão problema. Apenas um professor respondente ("2"), atingiu o índice atitudinal " 0,5 ", indicando parcialidade em sua resposta.

O índice atitudinal global para cada uma das respostas da questão "40211" do COCTS foi realizado através da média dos índices de cada uma das respostas atribuídas a referente questão, conforme preconizou Bispo-Filho (2012), gerando o Gráfico 2.

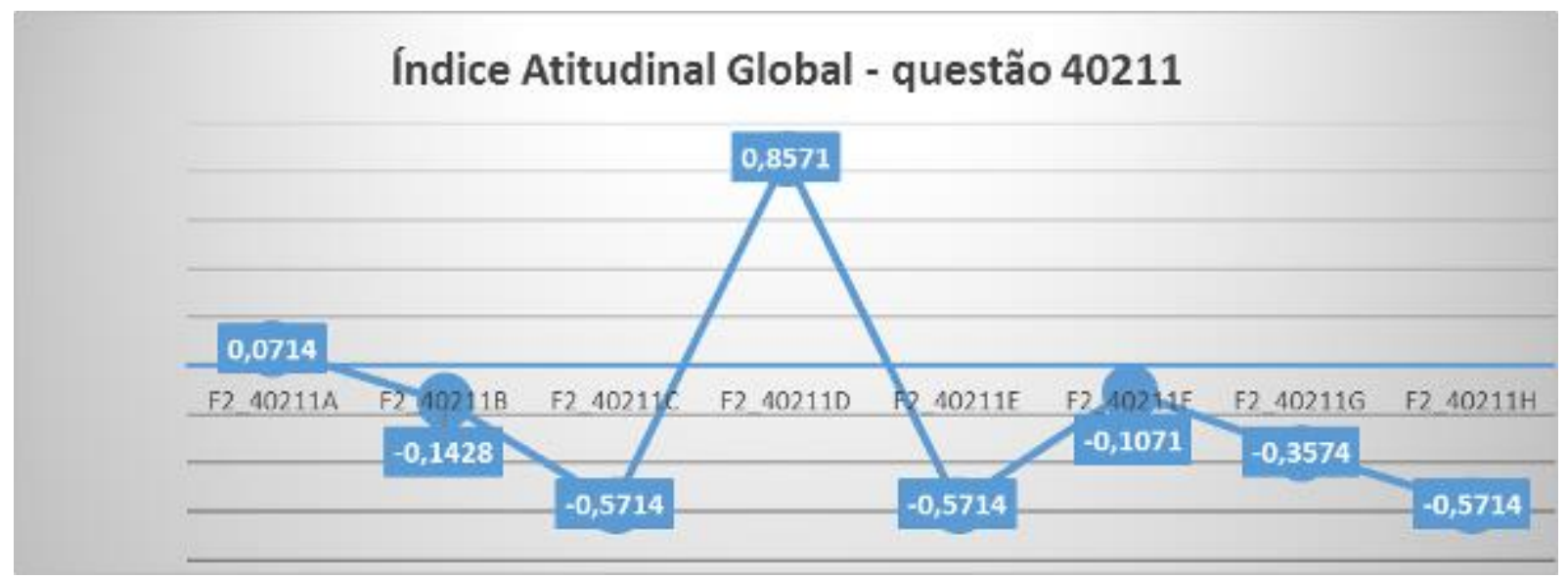

Gráfico 2: Índice atitudinal global gerado para cada uma das alternativas da questão "40211" do COCTS.

Analisando os índices atitudinais globais gerados para as alternativas da questão "40211", podemos observar que a maioria deles foram negativos, indicando uma atitude ingênua dos docentes para a questão. Apenas as alternativas "A": Os cientistas e engenheiros são os únicos profissionais que devem decidir sobre assuntos científicos porque possuem formação e conhecimentos que thes conferem uma melhor compreensão sobre temas de ciência e tecnologia, e a "D": As decisões devem ser tomadas de maneira compartilhada. As opiniões de cientistas, engenheiros, outros especialistas e cidadãos envolvidos devem ser levadas em conta nas decisões que afetam a nossa sociedade, alcançaram índices atitudinais positivos.

Para a questão "40321" do COCTS: "Em nosso país os gastos deveriam ser maiores com ciência e tecnologia do que com programas sociais, Revbea, São Paulo, V. 13, № 2: 137-152, 2018.

revista brasileira 
educação, incentivo à empresas e diminuição de impostos", para a alternativa A : "Deveria se gastar mais com ciência e tecnologia pois assim nosso país seria mais competitivo com o resto do mundo", considerada como "Plausível" pelo consenso dos juízes, foram gerados seis índices atitudinais negativos, sendo quatro índices "-1", dos professores respondentes "3", "4", "5" e "7" e dois índices "-0,5", dos professores " 1 " e "6", o que nos leva a acreditar em uma atitude ingênua dos mesmos para a problemática em questão: "Deveria se gastar mais com ciência e tecnologia pois assim nosso país seria mais competitivo com o resto do mundo". Já o professor respondente "2", atribuiu o valor "6" em sua resposta, demonstrando uma atitude "parcial" diante da questão, gerando o índice atitudinal " 0,5 ".

A alternativa B da questão "40321": "Deveria se gastar mais com ciência e tecnologia pois assim nosso país melhoraria a vida diária, por exemplo, fazer as coisas mais facilmente, criar novas indústrias e trabalho, ajudar a economia e resolver os problemas das enfermidades", considerada como "Plausível" pela maioria dos juízes do COCTS, gerou quatro índices atitudinais positivos, dos professores respondentes "2", "5", " 6 " e "7" e três índices atitudinais negativos, dos respondentes "1", "3" e "4".

A alternativa C: "Deveria se gastar mais com ciência e tecnologia, porém, só se o dinheiro gasto fosse usado para curar enfermidades, resolver os problemas da poluição ou dar comida aos famintos", também considerada "Plausível" pelo consenso dos juízes do COCTS, gerou três índices atitudinais negativos, dos professores respondentes "1", "4" e "5", indicando uma atitude ingênua dos mesmos diante da alternativa, que era: "Deveria se gastar mais com ciência e tecnologia, porém, só se o dinheiro gasto fosse usado para curar enfermidades, resolver os problemas da poluição ou dar comida aos famintos". Sendo que: o professor " 1 " concordou altamente com a alternativa ("8"), o professor "4" discordou altamente da alternativa ("2") e o professor "5" discordou totalmente da alternativa ("1"). Os demais respondentes obtiveram índices atitudinais positivos, pois demonstraram parcialidade em suas respostas.

A alternativa D: "O dinheiro deveria ser gasto de uma maneira equilibrada. Ciência e Tecnologia são muito importantes, porém não são as únicas coisas que precisam de dinheiro para o progresso de um país", considerada como "Adequada" pelo consenso dos juízes do COCTS, gerou apenas um índice atitudinal negativo ("-0,25), do professor respondente " 3 ", o que indica uma atitude parcialmente ingênua do mesmo sobre o problema abordado. Os demais professores alcançaram o índice atitudinal "1", indicando uma visão adequada dos mesmo para a questão, com exceção do professor respondente " 2 ", que gerou o índice atitudinal " 0,25 " com sua resposta, indicando uma atitude parcialmente adequada sobre o tema.

A alternativa E da questão "40321": "Deveria se menos dinheiro com a Ciência e a Tecnologia, de modo que se tenham mais dinheiro para se gastar com programas sociais, educação, incentivo as empresas e impostos mais baixos", considerada "Ingênua" pelos juízes do COCTS, gerou apenas dois Revbea, São Paulo, V. 13, № 2: 137-152, 2018. 
índices atitudinais negativos, sendo ambos "- 0,75 ", dos professores respondentes "2" e "4", que atribuíram o valor "8" (concordo altamente), em suas respostas. Os professores "3", "5" e "7" atribuíram o valor "1", discordando totalmente com a alternativa $D$, indicando uma atitude adequada frente ao problema abordado. Os professores "1" e "6" atribuíram o valor "2", discordando altamente da alternativa, indicando uma atitude altamente adequada dos mesmos diante da questão.

O índice atitudinal global para cada uma das respostas da questão "40321" do COCTS foi realizado através da média dos índices de cada uma das respostas atribuídas a referente questão, conforme preconizou Bispo-Filho (2012), gerando o Gráfico 3.

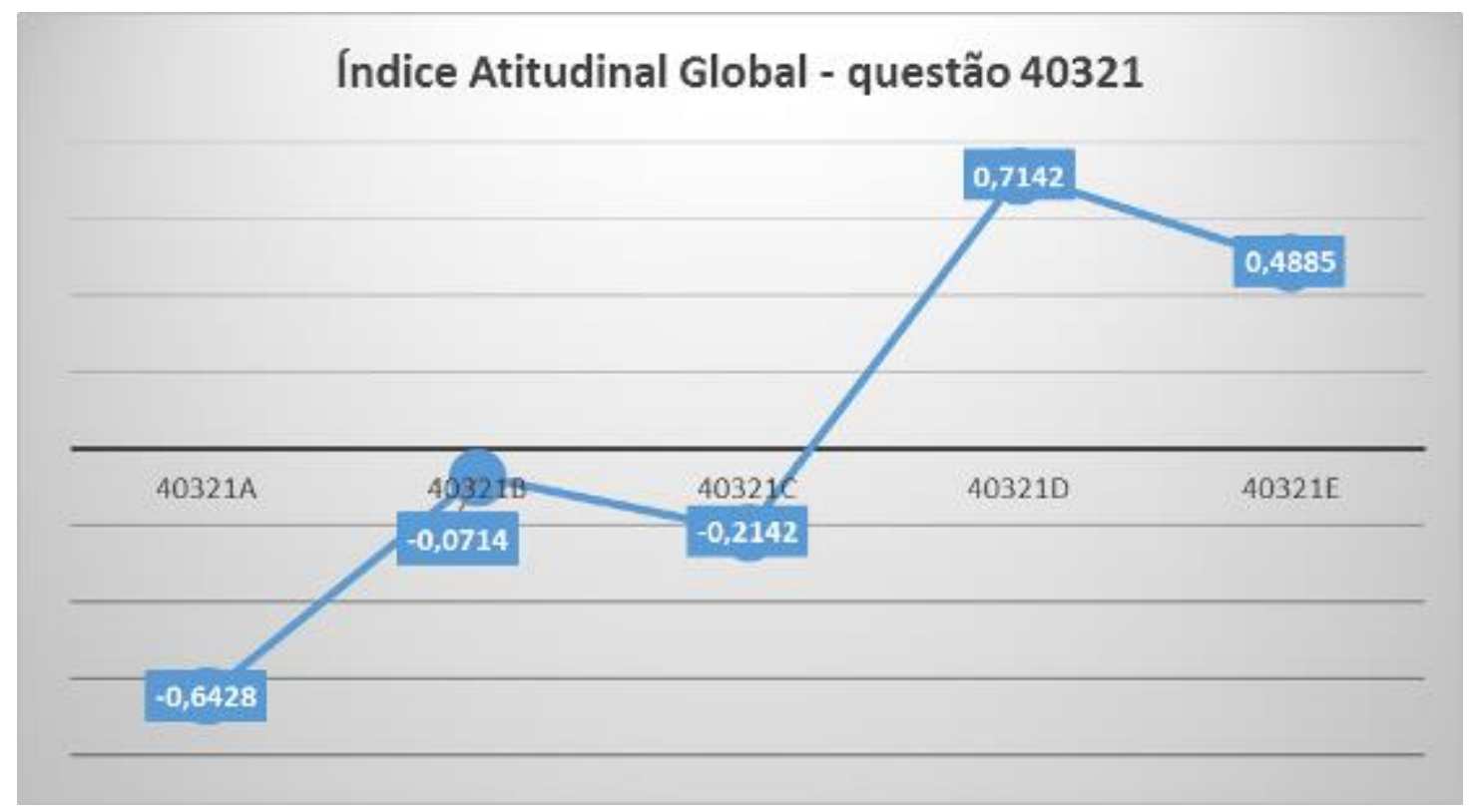

Gráfico 3: Índice atitudinal global gerado para cada uma das alternativas da questão "40321" do COCTS.

Analisando os índices atitudinais globais gerados para cada uma das alternativas da questão "40321", podemos observar que a maioria deles foram negativos, indicando uma atitude ingênua dos docentes para a questão: ": Em nosso país os gastos deveriam ser maiores com ciência e tecnologia do que com programas sociais, educação, incentivo à empresas e diminuição de impostos".

Para a questão "40411" do COCTS: "A ciência e a tecnologia são fundamentais para resolução de problemas sociais como a pobreza, a criminalidade, o desemprego, a superpopulação, a poluição ambiental e as ameaças de uma guerra nuclear", a alternativa A: "A ciência e tecnologia com certeza podem ajudar a resolver esses problemas. Pode-se usar novas ideias da ciência e novos inventos da tecnologia", considerada como "Plausível" pela 
maioria dos juízes do COCTS, gerou quatro índices atitudinais negativos, dos professores respondentes "1", "2", "3" e "5", o que nos leva a acreditar em uma atitude ingênua desses professores diante do problema analisado.

A alternativa B: "A ciência e a tecnologia podem ajudar a resolver alguns problemas sociais, porém, não todos", considerada como "Adequada" pela maioria dos juízes do COCTS, gerou apenas um índice negativo (-1), do professor respondente " 3 ", que discordou totalmente da alternativa. Os demais professores tenderam a concordar com a alternativa, demonstrando uma atitude adequada diante da mesma.

Para a alternativa C da questão "40411": "A ciência e a tecnologia resolvem muitos problemas sociais, porém, a ciência e a tecnologia causam muitos desses problemas", considerada "Adequada" pela maioria dos juízes do COCTS, houve, novamente, o predomínio de índices atitudinais negativos, onde os professores respondentes " 3 ", " 4 ", " 6 " e "7", tenderam a discordar com a opinião dos juízes, indicando uma atitude ingênua desses professores para a alternativa em questão.

A alternativa D: "Não é uma questão da ciência e tecnologia ajudarem, mas sim, como usá-las corretamente", considerada pelo consenso dos juízes do COCTS como "Plausível", gerou seis índices atitudinais individuais negativos nos levando a acreditar em uma atitude ingênua desses professores respondentes para a alternativa.

Já a alternativa E: "É difícil ver como a ciência e a tecnologia podem ajudar a resolver os problemas sociais. Os problemas sociais dizem respeito a natureza humana; esses problemas não têm nada a ver com a ciência e a tecnologia', considerada "Ingênua" pelo consenso dos juízes do COCTS, gerou seis índices atitudinais individuais positivos, demonstrando uma atitude adequada dos professores respondentes para a problemática debatida.

A alternativa F: "A ciência e a tecnologia fazem piorar os problemas sociais. É o preço que pagamos pelos avanços da ciência e da tecnologia", também considerada "Ingênua" pelo consenso dos juízes do COCTS, gerou, tal qual a alternativa E, seis índices atitudinais positivos, indicando, mais uma vez, uma atitude adequada da maioria dos professores respondentes para a questão.

A alternativa G: "Depende do tipo de problema. Em alguns casos poderá resolver, em outros não", classificada como "Plausível" pelo consenso dos juízes do COCTS, gerou quatro índices atitudinais individuais negativos, todos eles "-1", indicando uma atitude ingênua da maioria dos professores respondentes para a alternativa em questão.

Conforme preconizou Bispo-Filho (2012), o índice atitudinal global para cada uma das alternativas da questão "40411" do COCTS foi realizado através da média dos índices individuais de cada das alternativas, gerando o Gráfico 4: 


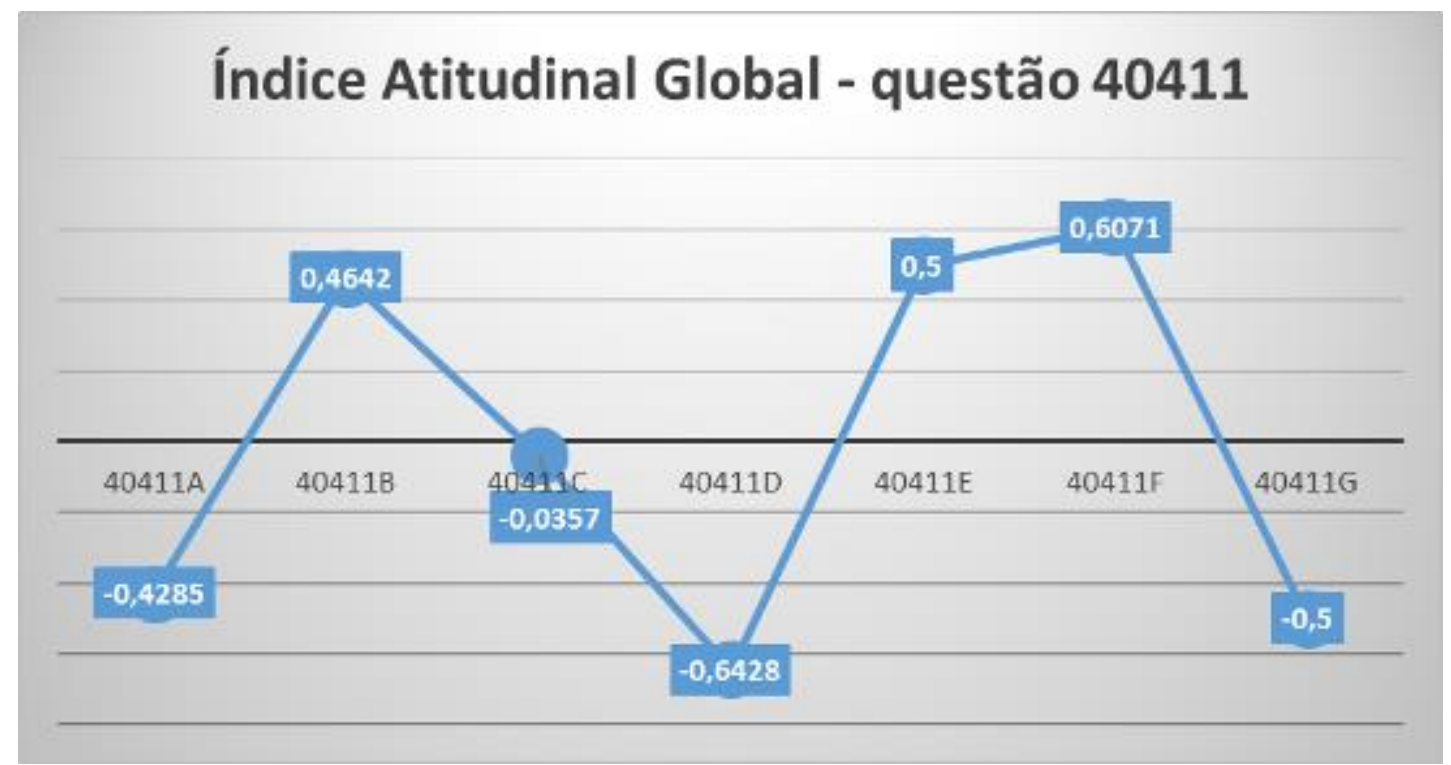

Gráfico 4: Índice atitudinal global gerado para cada uma das alternativas da questão "40411" do COCTS.

Analisando os índices atitudinais globais gerados para cada uma das alternativas da questão "40411", podemos observar que a maioria deles foram negativos, indicando uma atitude ingênua dos docentes para a questão. Porém, vale ressaltar aqui que, as duas alternativas consideradas como "Ingênuas" pelo consenso dos juízes do COCTS tiveram índices atitudinais globais positivos e portanto, adequados, ou seja, condizentes com a opinião dos juízes, indicando que a maioria dos docentes do curso de graduação em Engenharia Mecânica consideram a ciência e a tecnologia dois instrumentos que podem vir a ajudar a resolver os problemas sociais, porém, não resolverão todos os problemas mundiais, ou ainda, são, a ciência e a tecnologia, os únicos culpados pela geração desses problemas.

De uma maneira geral, a atitude dos professores do curso de graduação em Engenharia Mecânica são "Ingênuas" diante das questões socioambientais. Tais resultados podem ser atribuídos, conforme Sauvé (2005), a falta de visão da população sobre o meio ambiente como uma casa compartilhada, onde a Educação Ambiental induziria a dinâmicas sociais, de início, na comunidade local e depois em nível global, para mitigar o problema da poluição causada pela industrialização pesada. Buscando alternativas como a diminuição do consumo desenfreado de bens como celulares, por exemplo.

Além disso, cabe aqui ressaltar também a formação inicial e os saberes dos docentes envolvidos na pesquisa, pois, segundo Tardif (2002), os conhecimentos pedagógicos relacionados às técnicas e métodos de ensino e os conhecimentos relacionados à forma como as instituições de ensino fazem a gestão dos conhecimentos socialmente produzidos através dos planos de ensino e projetos pedagógicos influenciam a maneira como os docentes aplicam suas disciplinas. Assim, a concepção dos docentes do curso de 
Graduação em Engenharia Mecânica sobre Educação Ambiental está diretamente relacionada à política da IES em que atuam, ao histórico e objetivo pedagógico do curso e aos seus conhecimentos pedagógicos adquiridos.

Assim, os resultados obtidos, nos levam a acreditar que os professores não estão preparados para lidar com as mudanças necessárias que levam a abordagem das questões socioambientais. O que também é confirmado por Ruscheinsky (2012), que diz que muitos docentes possuem informações dos diversos problemas socioambientais, mas nem sempre discernimento das questões que estão imbricadas, nem tempo ou condições para se manterem atualizados com leituras que pudessem levá-los à reflexão.

\section{Considerações Finais}

Os resultados obtidos nos levam a acreditar que a concepção dos docentes do Curso de Graduação em Engenharia Mecânica sobre Educação Ambiental está relacionada ao histórico da profissão de engenheiro, à política educacional da IES em que o curso é ministrado, ao perfil do curso e à formação dos docentes, pois, embora a proposta curricular do curso demonstre preocupação com as questões socioambientais, na realidade, a aplicação do questionário, as análises das ementas e das práticas docentes demonstraram que as atitudes dos professores do curso de graduação em Engenharia Mecânica nem sempre priorizam assuntos relacionados a sociedade e ao meio ambiente.

Os professores dos cursos de graduação em Engenharia Mecânica, em sua maioria, são bacharéis em Engenharia, com experiência prática de destaque em alguma área da mesma, e não professores de formação, ou seja, não são licenciados, o que, em parte, pode contribuir para a falta da aplicação da temática ambiental em sala de aula, pois os cursos de licenciatura podem levar ao desenvolvimento de uma didática que leve a prática da Educação Ambiental por estes docentes.

Assim, o ideal seria que os docentes dos cursos de Engenharia recebessem uma formação continuada sobre Educação Ambiental, algo que possibilitasse a eles ter conhecimento da abordagem social, cultural, política, econômica e, também, ambiental, que envolve a mesma, bem como sua concepção e aplicação, pois é possível sim ministrar aulas que envolvam cálculos e resolução de problemas abordando questões socioambientais, basta saber como aplicar, corretamente, os princípios da Educação Ambiental, pois, segundo Zabala (1998), se o sistema educacional reproduz e legitima as desigualdades sociais, o professor sabe que com sua prática pode minorar essas desigualdades, deslegitimando-as com seus argumentos fundamentados e atitudes, havendo assim, chance para os valores socioambientais serem enraizados, dando origem a uma nova atitude da sociedade diante da temática ambiental. 


\section{Referências}

ACSELRAD, H. Sentidos da sustentabilidade urbana. In: ACSELRAD, H. (Org.). A duração das cidades: sustentabilidade e risco nas políticas urbanas. Rio de Janeiro: DP \& A, 2001. p. 27-55.

ANDRADE, K.M.A.B. Educação Ambiental: a formação continuada do professor. São Paulo: Paco Editorial, 2012.

BENNÀSSAR, A.R. et al. Introducción: educación científica y naturaleza de laciencia. In: BENNÀSSAR, A.R. et al. Ciencia, tecnología y sociedadenlberoamérica: una evaluación de lacomprensión de lanaturaleza de ciencia y tecnología. Madrid: OEI, 2010. n. 05, p. 15-56. Disponível em: $<$ http://www.oei.es/salactsi/DOCUMENTO5vf.pdf> Acesso em: 29 de abril de 2016.

BISPO-FILHO, D.O.; SEPINI, R.P.; MACIEL, M.D. Contribuições do COCTS como uma referencial teórico metodológico nas investigações relacionadas com a temática cts. In: AMARAL, C.L.; MACIEL, M.D. Coleção pesquisa e práticas em educação: ciência e tecnologias. São Paulo: TERRACOTA, 2011. p. 147-160.

BISPO-FILHO, D.O. Estudo do Impacto de Sequências Didáticas com Enfoque em Ciênncia, Tecnologia e Sociedade (CTS) / Natureza da Ciência e Sociedade (Ndc\&T) em Estudantes de Pedagogia. Tese (Doutorado em Ensino de Ciências e Matemática) - Universidade Cruzeiro do Sul, São Paulo - 2012.

BRAGA, B. et al. Introdução à Engenharia Ambiental. São Paulo: Pearson Prentice Hall, 2005.

CARVALHO, I. C. M. Educação ambiental: a formação do sujeito ecológico. 2.ed. São Paulo: Cortez, 2006.

CARVALHO, R.D. Formação Docente: Educação Ambiental na Engenharia Ambiental. Dissertação de Mestrado - Pontifícia Universidade Católica de São Paulo (PUC), Campinas - 2006.

GOLDENBERG, M. A arte de pesquisar: como fazer pesquisa qualitativa em ciências sociais. 3. ed. Rio de Janeiro: Record,1999.

LIMA, G.F.C. Questão Ambiental e Educação: Contribuições para o Debate. Ambiente \& Sociedade. Campinas, ano II, nำ, 135-153, 1999.

LUJÁN LÓPEZ, J.L.; LÓPEZ CEREZO, J.A. Educación CTS em acciónn: Enseñanza secunndaria y universidad. In: GONZÁLEZ GARCIA, M.I.: LÓPEZ CEREZO, J.A.; LUJÁN LÓPEZ, J.L. (Orgs.). Ciencia, Tecnologia y Sociedad: uma introducción al estúdio social de la ciencia y la tecnologia. Madrid: Editorial Tecnos S.A.. 1996. p. 225-252.

MANASSERO, M.A.; VÁZQUEZ, A.; ACEVEDO, J.A. Cuestionario de opiniones sobreciencia, tecnología y sociedad (COCTS). Princeton, NJ: Educational Testing Service, 2003. Disponível em: http://www.ets.org/testcoll/ . Acesso em: 23 set. 2016.

revista brasileira educação ambiental 
RUSCHEINSKY, A. (org.). Educação Ambiental: Abordagens Múltiplas. 2 e.d. São Paulo: Penso, 2012.

SAUVÉ, L. Educação Ambiental e Desenvolvimento Sustentável: uma análise complexa. $1997 . \quad$ Disponível em: $<$ http//www.cecae.usp.br/recicla/site/artigos/Lucie.Sauve.pdf $>$. Acesso em 21 de setembro de 2015.

SAUVÉ, L. Educação Ambiental: possibilidades e limitações. Revista Educação e Pesquisa, São Paulo.v.31, n.2, p. 317-322, 2005.

SEIFFERT, M.E.B. Gestão Ambiental: Instrumentos, Esferas de Ação e Educação Ambiental. São Paulo: Atlas, 2011.

SILVEIRA, R.M.C.F.; BAZZO, W.A. Inovação Tecnológica: Para Quem e Por Quê?. In: Anais do COBENGE - Congresso Brasileiro de Ensino de Engenharia, 2006, Passo Fundo - RS: UPF e Abenge, 2006.

TARDIF, M. Saberes Docentes e formação profissional. 4 e.d. Rio de Janeiro: Vozes, 2002.

VÁZQUEZ-ALONSO, A.; ACEVEDO-DÍAZ, J.A.; MANASSERO-MAS, M.A.; AVEVEDO-ROMERO, P. Evaluación de losefectos de lamateria CTS de bachillerato em lasactitudes CTS delalumnado com una metodologia de respuestamúltiple. Revista Eureka sobre Enseñanza y Divulgación de lasCiencias, v.03, n.03, p. 317 - 348, 2006.

VÁZQUEZ-ALONSO, A.; MANASSERO, M.A. Proyecto ibero americano de evaluación de actitudes relacionadas com La ciencia, La tecnología y La sociedad (PIEARCTS). Ministerio De Educación Y Ciencia/Espanha, 2006.

VÁZQUEZ-ALONSO, A.; MANASSERO, M.A; BENNÀSSAR, A.R. Unidades Didácticas Del proyecto Enseñanza y aprendizaje sobre La naturaleza de laciencia y tecnología (EANCYT). Ministerio de Ciencia e Innovación/Espanha, 2013.

ZABALA, A. A prática educativa: como ensinar. Porto Alegre: Artmed, 1998 